\title{
Socio-geographical factors in vulnerability to dengue in Thai villages: a spatial regression analysis
}

\author{
Mathuros Tipayamongkholgul ${ }^{1}$, Sunisa Lisakulruk ${ }^{2}$ \\ ${ }^{1}$ Department of Epidemiology, Faculty of Public Health, Mahidol University, Bangkok, Thailand; ${ }^{2}$ Provincial \\ Health Office, Muang District, Prachuap Khiri Khan Province, Thailand
}

\begin{abstract}
Focusing on the socio-geographical factors that influence local vulnerability to dengue at the village level, spatial regression methods were applied to analyse, over a 5-year period, the village-specific, cumulative incidence of all reported dengue cases among 437 villages in Prachuap Khiri Khan, a semi-urban province of Thailand. The K-order nearest neighbour method was used to define the range of neighbourhoods. Analysis showed a significant neighbourhood effect $(\rho=0.405$, $\mathrm{P}<0.001$ ), which implies that villages with geographical proximity shared a similar level of vulnerability to dengue. The two independent social factors, associated with a higher incidence of dengue, were a shorter distance to the nearest urban area $(\beta=-0.133, \mathrm{P}<0.05)$ and a smaller average family size $(\beta=-0.102, \mathrm{P}<0.05)$. These results indicate that the trend of increasing dengue occurrence in rural Thailand arose in areas under stronger urban influence rather than in remote rural areas.
\end{abstract}

Keywords: geographical information systems, spatial analysis, dengue, village level, Thailand.

\section{Introduction}

Dengue fever (DF) and dengue hemorrhagic fever (DHF) are of major public health concern in Southeast Asia since the 1950s (WHO, 2009). In the last 10 years, there has been an upsurge in reported cases of DF and DHF as well as an expansion of the geographical area at risk. Possible causes for this include urbanisation and a warmer climate, both of which can potentially facilitate the breeding of the principal dengue vector, Aedes aegypti (Gubler, 2002; Ooi and Gubler, 2008).

The urbanisation of Southeast Asia began in the 1950s and has accelerated in recent decades (Gubler, 2002; Ooi and Gubler, 2008). Urban communities with poor vector control due to lack of adequate public health infrastructure, such as tap water, sewage/waste management, and other services could be especially vulnerable to dengue (Gubler, 2002; Ooi and Gubler, 2008). In Thailand, a hyperendemic country for dengue in which four serotypes co-circulate (Chareonsook et al., 1999; Nisalak et al., 2003; Anatapreecha et al., 2004, 2005), mathematical modeling has shown the pivotal role played by large cities

\section{Corresponding author:}

Mathuros Tipayamongkholgul

Department of Epidemiology Faculty of Public Health

Mahidol University

420/1 Rajawithi Road, Bangkok 10400, Thailand

Tel./Fax +66 23548563

E-mail:phmty@mahidol.ac.th with respect to transmission and how waves of dengue epidemics tend to spread out from Bangkok and other large cities in a radial manner (Cummings et al., 2004). The role of urbanisation with regard to local vulnerability to dengue transmission in the rest of the region, however, was much less clear. Recent region- and district-level analyses (Chareonsook et al., 1999; Nagao et al., 2008) showed that the incidence of DHF and the intensity of transmission have been higher in rural regions than in Bangkok since the mid-1990s. The reasons for this apparent reversal in epidemiological pattern remain unknown.

In Thailand, villages within the same district or even the same sub-district can differ significantly with respect to social and environmental characteristics involved in dengue transmission, such as availability of transportation, a piped water system and solid waste management. A recent epidemiological study in Kamphaeng Phet province, north-central Thailand, highlighted the remarkably focal nature of dengue transmission (Keonraadt et al., 2008; Mammen et al., 2008). It is possible that the apparent increase in incidence of DHF cases in the rural regions actually occurred in villages located closer to cities, or being under stronger urban influence, rather than in truly remote rural areas. To examine this hypothesis, we applied spatial regression to analyse socio-geographic predictors for the occurrence of all reported dengue cases at the village level in Prachuap Khiri Khan, a semi-urban province in coastal Thailand, from 2003 to 2007. Because neighbouring villages can share a simi- 
lar social and ecological environment, with resulting similarity in their incidences of dengue, analyses for socio-geographic factors in the occurrence of dengue required the use of spatial regression methods, which include spatial lag terms in the regression models to adjust for the effect of spatial neighbourhood (de Almeida et al., 2009).

\section{Materials and methods}

\section{Study area}

Prachuap Khiri Khan was selected from the 76 provinces of Thailand as our study area. This province is located along the western coastline of the Gulf of Thailand (Fig. 1) and has an area of $6,368 \mathrm{~km}^{2}$, including agricultural fields $(44.8 \%)$, forested areas $(42.3 \%)$ and residential areas $(7 \%)$. The province comprises eight districts, 48 sub-districts and 437 villages, with three metropolitan areas and 13 municipalities.

As a result of rural development projects, the province has now basic infrastructure, such as main roads, electricity and tap water, a development that has encouraged tourism and industrialisation focusing on preserved-fruit and pineapple products (Information Technology and Communication, 2008). The economic growth has influenced social patterns in many areas of Prachuap Khiri Khan province changing rural areas to semi-urban, and semi-urban areas to urban. These social changes, along with a decentralised dengue control policy, may have had a detrimental effect with respect to dengue incidence. During 2005-2007, the Ministry of Public Health, Thailand, declared Prachuap Khiri Khan a high-risk area for dengue (Bureau of Epidemiology, 1996-2005).

\section{Data collection}

Surveillance. Since 1967, Thailand has had a wellestablished dengue surveillance system. Dengue is a notifiable disease, i.e. once a case has been identified, based on the World Health Organization (WHO) clinical criteria (WHO, 2000), it must be reported by to Provincial Health Office (PHO). A case of DF is defined as presence of acute fever plus at least two of the following clinical findings: high fever, severe headache, back-eye pain, muscle pain, positive tourniquet test, and a white blood cell count of $<5,000 / \mu$ l of blood, while a case of DHF is defined as presence of acute fever with a positive tourniquet test, one of the clinical findings mentioned above, and a $10-20 \%$ elevation of the haematocrit (WHO, 2000).

The number of dengue cases in Prachuap Khiri Khan from January 2003 to December 2007 was obtained from a PHO surveillance database. The 2007 demographic data obtained from this $\mathrm{PHO}$ were used as a standard population to calculate the cumulative dengue incidence. Because of the low population growth rate $(<1 \%)$ in Prachuap Khiri Khan, demo-
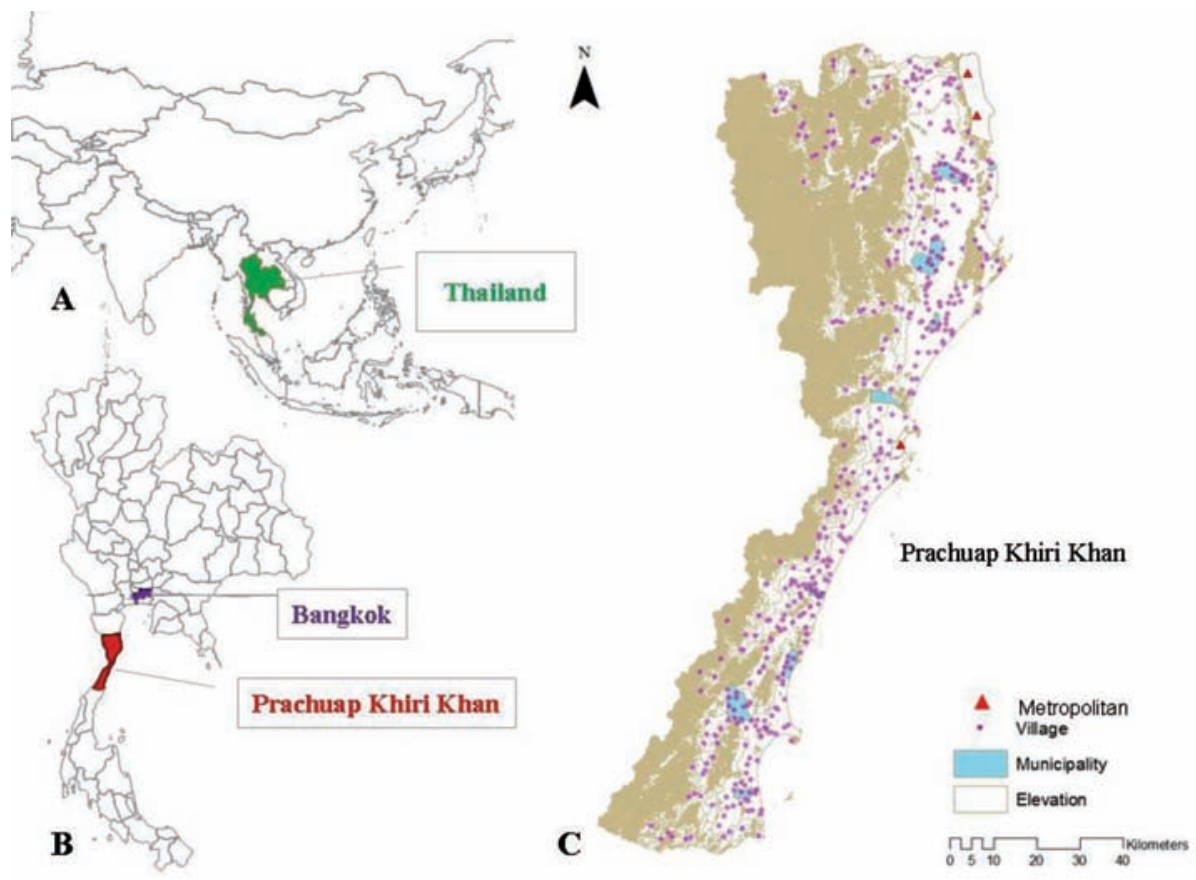

Fig. 1. The study area and its location in the larger context of Southeast Asia. 
graphics for each village were assumed to be stable over the 5 years of the study period (Information Technology and Communication, 2008).

The number of all reported dengue cases, including DF and DHF, from January 2003 to December 2007 were summed and the village-specific cumulative dengue incidence $I_{i}$ calculated by the formula:

$$
I_{i}=\frac{O_{i}}{P_{i}},
$$

where $O_{i}$ is the cumulative number of dengue cases during 2003-2007 in village $i$ ( $i$ could vary between 1 and 437) and $P_{i}$ the population of this village in 2007.

Spatial data. Topographic maps with spatial features such as schools, factories, wells, main roads, public clinics and hospitals, and urban areas (both metropolitan and municipalities) were obtained from the PHO in Prachuap Khiri Khan and geographical information systems (GIS) using ArcGIS, Desktop 9.3 software (ArcGIS, 2009). First by, the geographic center of each village and its spatial features were defined. Secondly, the distances between the center point to the closest school, factory, well, urban area, health center and main road were measured. Finally, the number of schools, factories and public health centers within a $5-\mathrm{km}$ radius of the geographic center of each village was counted. All variables used in this study are shown in Table 1.

Table 1. Abbreviations for socio-geographic variables.

\begin{tabular}{|c|c|}
\hline Variables & Definition (unit) \\
\hline $\mathrm{HH}$ & Ratio of population to houses in a village \\
\hline House & $\begin{array}{l}\text { Number of houses in a village } \\
\text { (per } 1,000 \text { units) }\end{array}$ \\
\hline Num_Fac & $\begin{array}{l}\text { Number of factories within a } 5-\mathrm{km} \text { radius of a } \\
\text { village (per 1,000 units) }\end{array}$ \\
\hline Num_Sch & $\begin{array}{l}\text { Number of schools within a } 5-\mathrm{km} \text { radius of a } \\
\text { village (per 1,000 units) }\end{array}$ \\
\hline Sch_Nearest & Distance from a village to the nearest school $(\mathrm{km})$ \\
\hline PHC_Dist & $\begin{array}{l}\text { Distance from a village to the nearest health } \\
\text { center }(\mathrm{km})\end{array}$ \\
\hline Muni_Nearest & $\begin{array}{l}\text { Distance from a village to the nearest urban } \\
\text { area* }(\mathrm{km})\end{array}$ \\
\hline Well_Nearest & Distance from a village to the nearest well $(\mathrm{km})$ \\
\hline Fac_Nearest & Distance from a village to the nearest factory $(\mathrm{km})$ \\
\hline Road_Nearest & Distance from a village to the nearest road $(\mathrm{km})$ \\
\hline
\end{tabular}

*Urban area $=$ either metropolitan area or municipality

\section{Data analysis}

Ordinary linear model. The village-specific dengue incidence rates were first transformed to natural logarithm functions. The regression model was based on the formula:

$$
\ln (\hat{\mathrm{Y}})=\alpha+\beta_{1} \mathrm{X}_{1}+\beta_{2} \mathrm{X}_{2}+\ldots+\beta_{n} \mathrm{X}_{n}+\varepsilon
$$

where $Y$ is the cumulative dengue incidence in a village, $\beta_{1 \text { to } n}$ the regression coefficients of the socio-geographic variables $X_{1 \text { to } n}$ and $\varepsilon$ the error term.

In the multiple regression analysis, all studied sociogeographic variables (see Table 1 for more detail) were included in the maximum model. A stepwise technique was used to select a minimally adequate model with the smallest Akaike's information criterion (AIC) value, with $P$ values of 0.10 and 0.05 as the entry and removal criteria, respectively. The selected model identified the multicollinearity by examining the variance inflation factor (VIF), i.e. a VIF value near 1 indicates absence of multicollinearity. The selected model was then proceeded in fitting the spatially lagged model.

Spatial neighbours. To define a biologically plausible spatial neighbourhood, we applied the K-order nearest-neighbour (KNN) method rather than using the linear distance between villages (Gatrell et al., 1996) because of the similar ecological and socio-cultural factors shared by nearby villages (Kan et al., 2008). KNN was assigned an order from 1 to 10 . Each KNN set was used to construct a spatial weight matrix (SWM), in which the value was 1 for neighbours and 0 otherwise. The optimal radius, which might reflect the flying range of infected mosquitoes, was determined by fitting spatial regression models with different sets of SWMs to find the optimal model with the smallest AIC value.

Spatial autocorrelation. Moran's I was employed to examine the spatial dependence of the residuals from the fitted ordinary linear model, as follows:

$$
I=\frac{n}{S_{0}} \frac{\sum_{i=1}^{n} \sum_{i=1}^{n} w_{i j}\left(x_{i}-\bar{x}\right)\left(x_{j}-\bar{x}\right)}{\sum_{i=1}^{n}\left(x_{i}-\bar{x}\right)^{2}}, \quad S_{0}=\sum_{i=1}^{n} \sum_{i=1}^{n} w_{i j}
$$

where $w_{i j}$ is the SWM between villages $i$ and $j(i \neq j), \bar{x}$ the mean value of village-specific incidence, and $S_{0}$ the sum of all SWMs. Significant Moran's I statistics indicated the presence of spatial autocorrelation in the dengue incidences, and thus dictated the use of a spatially lagged model in the regression. Ten sets of SWMs with KNN orders 1 to 10 were tested using Moran's I to identify spatial dependence of the residu- 
als with varying numbers of neighbours.

Spatially lagged model. To take spatial dependence into account in the regression analysis, we applied a spatially lagged model, including a spatial autoregressive term $\rho w_{i j} \mathrm{Y}$ in the fitted ordinary linear model (Ward and Gleditsch, 2008), as follows:

$$
\ln (\hat{\mathrm{Y}})=\alpha+\beta_{1} \mathrm{X}_{1}+\beta_{2} \mathrm{X}_{2}+\ldots+\beta_{n} \mathrm{X}_{n}+\rho w_{i j} \mathrm{Y}+\varepsilon
$$

where $\mathrm{Y}$ is the cumulative village dengue incidence, $\beta_{1 \text { to } n}$ the regression coefficients of socio-geographic variables $X_{1 \text { to } n}$, respectively, $w_{i j}$ the SWM between villages $i$ and $j(i \neq j), \rho$ the coefficient of spatial dependence, and $\varepsilon$ the spatial autoregressive error term. All statistical analyses were performed using the R software package spdep (Bivand, 2004) and ArcGIS desktop, version 9.3 (ArcGIS, 2009).

\section{Results}

The epidemiological characteristics of the 4,398 dengue cases reported in Prachuap Khiri Khan from January 2003 to December 2007 are shown in Table 2 . Of the 362 villages with reported dengue cases during the study period, cumulative incidence of dengue cases per village ranged from $0.06 \%$ to $3.44 \%$ [mean \pm standard deviation $=0.51 \% \pm 0.47 \%]$. The age of patients in the reported dengue cases ranged from 3 months to 75 years (median $=13$ years). The proportion of adults $\geq 15$ years was $40 \%$. We did not find any difference in dengue risk between gender. Although the dengue season starts in April and lasts till September, cases occurred all year round (Table 2).
Of the 4,398 dengue cases reported during the study period, 27 were excluded from the analysis due to lack of geographical data. We first applied ordinary linear models to analyse the association between socio-geographic factors and dengue incidence among the villages. In the univariate analysis, the distance to the nearest urban area $(P=0.03)$ and the average number of persons per house ( $\mathrm{P}=0.002)$ were inversely associated with village-specific dengue incidence (Table 3 ). In the multiple regression analysis, the distance to the nearest urban area $(\beta=-0.171, \mathrm{P}<0.05)$ and the average number of persons per house $(\beta=-0.122$, $\mathrm{P}<0.001)$ remained the two independent predictors of village-specific dengue incidence (Table 4).

Spatial autocorrelation was then examined with 10 orders of KNN. Moran's $I$ index was significant $(\mathrm{P}<0.05)$ at all KNN orders, indicating the presence of spatial dependence in the residual and the necessity to use a spatially lagged model in regression. The AIC values of spatially lagged models using different orders of KNN were compared. The model with the KNN order of 8 (an average radius of $5.5 \mathrm{~km}$ ) had the lowest AIC value (Fig. 2) and was therefore used in our further analysis. The coefficient of spatial dependence was highly significant $(\rho=0.405, \mathrm{P}<0.001)$ (Table 4), indicating the presence of a neighbourhood effect. After adjusting for the neighbourhood effect, the distance to the nearest urban area $(\beta=-0.133, \mathrm{P}<0.05)$ and the average number of persons per house $(\beta=-0.102, \mathrm{P}$ $<0.05)$ still remained independent predictors for the local incidence of dengue at the village level. This model presented the better performance than the ordinary least square, with the smaller AIC value (Table 4).

Table 2. Epidemiological pattern of reported dengue cases in Prachuap Khiri Khan, Thailand, during 2003-2007.

\begin{tabular}{|c|c|c|c|}
\hline Variable & Regression coefficient & SE & $P$ value \\
\hline $\mathrm{HH}$ & -0.105 & 0.034 & $0.002 *$ \\
\hline House & -0.003 & 0.027 & 0.917 \\
\hline Num_Fac & -0.387 & 3.728 & 0.917 \\
\hline Num_Sch & -6.084 & 10.045 & 0.545 \\
\hline Sch_Nearest & -0.013 & 0.017 & 0.453 \\
\hline PHC_Dist & -0.030 & 0.019 & 0.105 \\
\hline Muni_Nearest & -0.013 & 0.006 & $0.030^{*}$ \\
\hline Well_Nearest & -0.006 & 0.030 & 0.830 \\
\hline Fac_Nearest & -0.014 & 0.008 & 0.073 \\
\hline Road_Nearest & -0.024 & 0.030 & 0.417 \\
\hline
\end{tabular}

* Statistically significant; SE, standard error. 
Table 3. Univariate analysis of the association between socio-geographic variables and dengue incidence in villages.

\begin{tabular}{|c|c|c|}
\hline Variables & Baits $/ \mathrm{km}^{2}$ & Number $(\%)$ \\
\hline \multirow[t]{2}{*}{ Village } & With dengue cases & $362(82.8)$ \\
\hline & Without dengue cases & $75(17.2)$ \\
\hline Village-specific dengue incidence $(\%)$ & Mean \pm SD & $0.51 \pm 0.47$ \\
\hline \multirow[t]{2}{*}{ Gender } & Male & $1,361(54.5)$ \\
\hline & Female & $1,137(45.5)$ \\
\hline \multirow[t]{8}{*}{ Age (years) } & $0-4$ & $205(8.2)$ \\
\hline & $5-9$ & $595(23.8)$ \\
\hline & $10-14$ & 705 (28.2) \\
\hline & $15-19$ & $410(16.4)$ \\
\hline & $20-29$ & $355(14.2)$ \\
\hline & $\geq 30$ & $228(9.1)$ \\
\hline & Median & 13 \\
\hline & (Min-Max) & ( 3 months -75 years) \\
\hline \multirow[t]{12}{*}{ Month } & January & $97(3.9)$ \\
\hline & February & $107(4.3)$ \\
\hline & March & $149(6.0)$ \\
\hline & April & $194(7.8)$ \\
\hline & May & $307(12.3)$ \\
\hline & June & $359(14.4)$ \\
\hline & July & $344(13.8)$ \\
\hline & August & $298(11.9)$ \\
\hline & September & $268(10.7)$ \\
\hline & October & $131(5.2)$ \\
\hline & November & $150(6.0)$ \\
\hline & December & $94(3.8)$ \\
\hline
\end{tabular}

SD, standard deviation.

Table 4. Spatial regression analysis for predictors of dengue incidence in villages.

\begin{tabular}{|c|c|c|c|c|}
\hline \multirow{2}{*}{ Variables } & \multicolumn{2}{|c|}{ Ordinary linear model } & \multicolumn{2}{|c|}{ Spatially lagged model } \\
\hline & Coefficient & SE & Coefficient & SE \\
\hline Intercept & -4.63 & 0.149 & -2.63 & 0.398 \\
\hline $\mathrm{HH}$ & $-0.122 * *$ & 0.034 & $-0.102 *$ & 0.033 \\
\hline Muni_Nearest & $-0.171 *$ & 0.06 & $-0.133 *$ & 0.059 \\
\hline Rho & 1065.7 & & $0.405 * *$ & \\
\hline AIC & & & 1051.1 & \\
\hline
\end{tabular}

*P $<0.05, * \mathrm{P}<0.001 ; \mathrm{SE}$, standard error; HH, population-to-house ratio; Muni_Nearest, distance to the nearest urban area; Rho, coefficient of spatial dependence; AIC, Akaike's information criterion. 


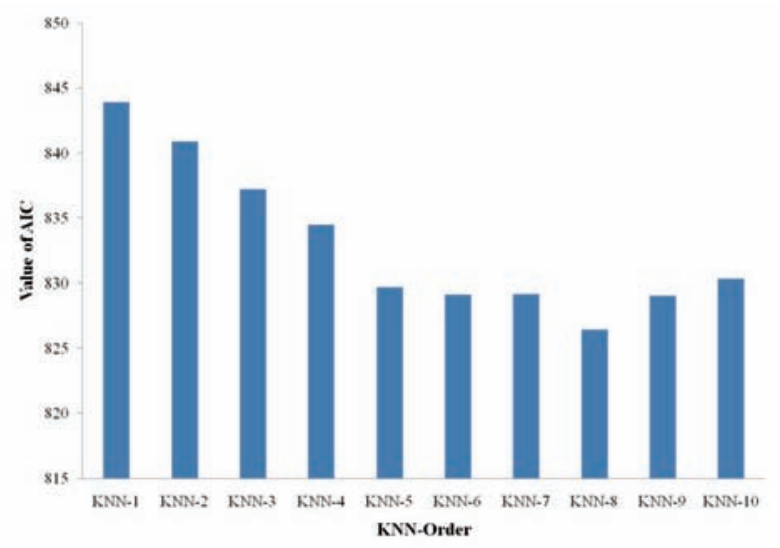

Fig. 2. Akaike's information criterion (AIC) values of spatial autoregressive models at $\mathrm{KNN}$ order from 1 to 10 . $\mathrm{X}$-axis is the $\mathrm{KNN}$ order, Y-axis is the value of AIC.

\section{Discussion}

This study was undertaken since there has been no research at the village level on the socio-geographic factors of local vulnerability to dengue transmission. The analysis showed a significant neighbourhood effect ( $\rho=0.405, \mathrm{P}<0.001)$, which implies that villages at geographical proximity shared a similar level of vulnerability to dengue. Another notable finding was the associations between higher village-specific dengue incidences and two socio-geographic factors, namely proximity to the nearest urban areas, and a smaller average number of persons per house in the villages. Both of these factors imply a stronger urban influence, the latter because urban areas in Thailand have a smaller average family size than rural areas (Robey, 1990).

The neighbourhood effect may be explained by similarities in human behaviour, social patterns and social interactions among neighbouring villages (Carbajo et al., 2006; Kan et al., 2008; Mondini and ChiaravallotiNeto, 2008). It has been reported that neighbours in the same area generally share similar ecology and lifestyle (Dietz, 2002; Reiter et al., 2003), and such characteristics may give rise to a positive or negative association with the occurrence of dengue in neighbouring areas. For instance, villages in a particular area may have comparable infrastructure, such as availability of tap water, accessible wells, and sanitary systems, which may result in similar risks of dengue transmission in the proximal areas. Furthermore, in Thailand, neighbouring villages usually have common social and/or religious centers such as temples, mosques and community halls where villagers often gather. Therefore, the status of vector control in one such place can influence the level of vulnerability to dengue in the entire neighbourhood (Halstead et al., 1969).
In contrast to previous region- and district-level studies (Chareonsook et al., 1999; Nagao et al., 2008), the present investigation presents a village-level analysis. The association found between dengue incidence and proximity to the nearest urban areas implies that the villages surrounding cities have a higher dengue risk than those located far away from urban areas. Thus, rather than in remote rural areas, the previously observed trend in the increased dengue occurrence in rural Thailand may have actually started in areas of strong urban influence. Our findings provide evidence for the role of urbanisation in the worsening dengue situation in Southeast Asia. In the newly urbanised areas, the larger population and increased number of dwellings provide an abundance of artificial breeding sites due to the storage of water, solid waste and lack of sufficient environmental management (Halstead et al., 1969; Kendall et al., 1991; Gubler and Meltzer, 1999; Nakapakorn and Tripathi, 2005; Mondini and Chiaravalloti-Neto, 2008; Thammapalo et al., 2008). As a result, these areas become vulnerable to dengue transmission. In addition, new urban areas often do not have sufficient medical resources for the early detection of dengue, resulting in delayed public health response in the initial phase of an epidemic, which allows the transmission cycle to continue and expand (Gubler, 2006; Ooi et al., 2006; Thammapalo et al., 2008). Moreover, people located near urban areas usually travel back and forth to cities for work, and may thus bring the disease to their residential areas (Gubler, 2006; Ooi and Gubler, 2008). In contrast, villages located far away from urban areas are generally dispersed, which may slow down the transmission and allow public health services to provide appropriate prevention and control measures. In addition, under-reporting of dengue in remote areas may affect the association between urban areas and dengue risk, because, in general, people who live in remote areas have lower levels of access to health care services. However, this was less likely to occur in this study due both to the location of health centers and the obligation of the health staff. In our study area, most of the health centers were located close to the villages (an average radius of $1.06 \mathrm{~km}$ corresponding to a 10 min walking distance), and each health center there is required to have at least one person able to identify dengue symptoms and refer suspected cases for diagnosis (Information Technology and Communication, 2008). Secondly, it is an obligation for health staff to report all dengue cases to the PHO (Bureau of Epidemiology, 1996-2005).

This study did not find an association between 
dengue occurrence and wells, as had been identified in a previous district-level study (Nagao et al., 2008). This is not surprising since public and private wells in Thailand are constructed with the purpose of providing water for daily life in rural areas and the small population in each village is barely sufficient to sustain transmission once an index case occurs.

The lack of information about transportation networks in study areas was a limitation of this study that might have resulted in underestimation of the neighbourhood effect. Also, we did not have accurate local mosquito index data, and were therefore unable to analyse the effects of vector-control interventions. Moreover, geographic information on reported cases of dengue relied on verbal information during registration, which might not have been as accurate as data obtained through field survey interviews. One study has reported that a higher percentage of shop-houses, brick-made houses and houses with poor garbage disposal in a district are associated with an increased incidence of dengue (Thammapalo et al., 2008). However, because we did not have access to data on the type of houses for this study, we were unable to confirm this finding at the village level. Finally, our study is a crosssectional analysis of only 5-year aggregated data. Because urbanisation is a longitudinal process taking place over decades, a prospective longitudinal study over a sufficiently long period would be required to directly measure the ecological impact of urbanisation with respect to dengue incidence.

\section{Conclusions}

Our study has demonstrated a neighbourhood effect in the occurrence of dengue cases. Using village-level data, we also found that villages surrounding urban areas and/or having a smaller average family size were more vulnerable to dengue than villages located far away from urban areas and/or having a larger average family size. These results indicate that the trend towards increased dengue incidence in rural Thailand, observed in the previous region- and district-level analyses, actually tarted in areas under stronger urban influence rather than in remote rural areas.

\section{Acknowledgements}

We would like to thank the staff of the Prachuap Khiri Khan Provincial Health Office for their kind support and efforts towards dengue prevention and control. We sincerely express our gratitude to all members in the infectious disease meeting for their excellent comments on this study. We also thank the
Department of Health, Executive Yuan and National Taiwan University, Infectious Diseases Research and Education Center for their general support.

\section{References}

Anantapreecha S, Chanama S, A-nuegoonpipat A, Naemkhunthot S, Sa-Ngasang A, Sawaspayalert P, Kurane I, 2004. Annual changes of predominant dengue virus serotypes in six regional hospitals in Thailand from 1999 to 2002. Dengue Bull 28, 1-6.

Anantapreecha S, Chanama S, A-nuegoonpipat A, Naemkhunthot S, Sa-Ngasang A, Sawaspayalert P, Kurane I, 2005. Serological and virological features of dengue fever and dengue haemorrhagic fever in Thailand from 1999 to 2002. Epidemiol Infect 133, 503-507.

ArcGIS, 2009. Environmental Systems Research Institute, Inc., Redlands, CA, USA.

Bivand R, 2004. Spdep: spatial dependence: weighting schemes, statistics and models. R package version 0.2-22. Retrieved 1011-09, from http://cran.r-project.org/src/contrib/Descriptions/ spdep.html.

Bureau of Epidemiology, 1996-2005. Annual Epidemiological Surveillance Reports, Ministry of Public Health, Bangkok, Thailand.

Carbajo AE, Curto SI, Schweigmann NJ, 2006. Spatial distribution pattern of oviposition in the mosquito Aedes aegypti in relation to urbanization in Buenos Aires: southern fringe bionomics of an introduced vector. Med Vet Entomol 20, 209-218. Chareonsook O, Foy HM, Teeraratkul A, Silarug N, 1999. Changing epidemiology of dengue hemorrhagic fever in Thailand. Epidemiol Infect 122, 161-166.

Cummings DA, Irizarry RA, Huang NE, Endy TP, Nisalak A, Ungchusak K, Burke DS, 2004. Travelling waves in the occurrence of dengue haemorrhagic fever in Thailand. Nature 427, 344-347.

de Almeida AS, Medronho Rde A, Valencia LI, 2009. Spatial analysis of dengue and the socioeconomic context of the city of Rio de Janeiro (Southeastern Brazil). Rev Saude Publica 43, 666-673.

Dietz R, 2002. The estimation of neighbourhood effects in the social sciences: an interdisciplinary approach. Soc Sci Res 31, 539-575.

Gatrell AC, Bailey TC, Diggle P, Rowlingson BS, 1996. Spatial point pattern analysis and its application in geographical epidemiology. Trans Inst Br Geogr 2, 256-274.

Gubler DJ, 2002. Epidemic dengue/dengue hemorrhagic fever as a public health, social and economic problem in the 21 st century. Trends Microbiol 10, 100-103.

Gubler DJ, 2006. Dengue/dengue haemorrhagic fever: history and current status. Novartis Found Symp 277, 3-16.

Gubler DJ, Meltzer M, 1999. Impact of dengue/dengue hemor- 
rhagic fever on the developing world. Adv Virus Res 53, 35-70.

Halstead SB, Scalon JE, Umpaivit P, Udomsakdi S, 1969. Dengue and chikungunya virus infection in man in Thailand, 1962-1964. IV. Epidemiologic studies in the Bangkok metropolitan area. Am J Trop Med Hyg 18, 997-1021.

Information Technology and Communication, 2008. Annual Report of Prachuap Khiri Khan. Prachuap Khiri Khan Provincial Office, Prachuap Khiri Khan, Thailand.

Kan CC, Lee PF, Wen TH, Chao DY, Wu MH, Lin NH, Huang YJ, Shang CS, Fan IC, Shu PY, Huang JH, King CC, Pai L, 2008. Two clustering diffusion patterns identified from the 2001-2003 dengue epidemic, Kaohsiung, Taiwan. Am J Trop Med Hyg 79, 344-352.

Kendall C, Hudelson P, Leontsini E, Winch P, Lloyd L, Cruz F, 1991. Urbanization, dengue, and the health transition: anthropological contributions to international health. Med Anthropol Q 5, 257-268.

Keonraadt CJM, Aldstadt J, Kijchalao U, Sithiprasasna R, Getis A, Jones JW, Scott TW, 2008. Spatial and temporal patterns in pupal and adult production of the dengue vector Aedes aegypti in Kamphaeng Phet, Thailand. Am J Trop Med Hyg 79, 230-238.

Mammen MP, Pimgate C, Koenraadt CJM, Rothman AL, Aldstadt J, Nisalak A, Jarman RG, Jones JW, Srikiatkhachorn A, Ypil-Butac CA, Getis A, Thammapalo S, Morrison AC, Libraty DH, Green S, Scott TW, 2008. Spatial and temporal clustering of dengue virus transmission in Thai villages. PLoS Med 5, e205

Mondini A, Chiaravalloti-Neto F, 2008. Spatial correlation of incidence of dengue with socioeconomic, demographic and environmental variables in a Brazilian city. Sci Total Environ 393, 241-248.

Nagao Y, Svasti P, Tawatsin A, Thavara U, 2008. Geographical structure of dengue transmission and its determinants in Thailand. Epidemiol Infect 136, 843-851.
Nakhapakorn K, Tripathi NK, 2005. An information value based analysis of physical and climatic factors affecting dengue fever and dengue haemorrhagic fever incidence. Int $\mathrm{J}$ Health Geogr 4, 13.

Nisalak A, Endy TP, Nimmannitya S, Kalayanarooj S, Thisayakorn U, Scott RM, Burke SD, Hoke CH, Innis BL, Vaughn DW, 2003. Serotype-specific dengue virus circulation and dengue disease in Bangkok, Thailand from 1973 to 1999. Am J Trop Med Hyg 68, 191-202.

Ooi EE, Goh KT, Gubler DJ, 2006. Dengue prevention and 35 years of vector control in Singapore. Emerg Infect Dis 12, 887 893.

Ooi EE, Gubler DJ, 2008. Dengue in Southeast Asia: epidemiological characteristics and strategic challenges in disease prevention. Cad Saúde Pública 25, 115-124.

Reiter P, Lathrop S, Bunning M, Biggerstaff B, Singer D, Tiwari T, Baber L, Amadot M, Thirion J, Hayes J, Seca C, Mendez J, Ramirez B, Robinson J, Rawlings J, Vorndam V, Waterman S, Gubler D, Clark G, Hayes E, 2003. Texas lifestyle limits transmission of dengue virus. Emerg Infect Dis 9, 86-89.

Robey B, 1990. Family size and well-being: evidence from Thailand. Asia-Pacific Pop Pol 12, 4.

Thammapalo S, Chongsuvivatwong V, Geater A, Dueravee M, 2008. Environmental factors and incidence of dengue fever and dengue haemorrhagic fever in an urban area, Southern Thailand. Epidemiol Infect 136, 135-143.

Ward MD, Gleditsch KS, 2008. Spatial regression models. Quantitative Applications in the Social Sciences. Thousand Oaks CA: SAGE Publications Inc, 35-47 pp.

WHO, 2000. Dengue Haemorrhagic Fever: Diagnosis, Treatment, Prevention and Control. $2^{\text {nd }}$ edition, Geneva, Switzerland.

WHO, 2009. Dengue and Dengue Haemorrhagic Fever Fact Sheets. http://www.who.int/mediacentre/factsheets/fs117/en/ (accessed: 21 May 2009). 